\title{
Perceived Crowd Safety in Large Space Buildings: The Confirmatory Factor Analysis of Perceived Risk Variables
}

\author{
Mohammed Alkhadim ${ }^{1}$, Kassim Gidado ${ }^{2}$, and Noel Painting ${ }^{3}$ \\ ${ }^{1}$ School of Environment and Technology, University of Brighton, United Kingdom. E-mail: M.Al- \\ Khadim@brighton.ac.uk (corresponding author). \\ ${ }^{2}$ Principal Lecturer, School of Environment and Technology, University of Brighton, United Kingdom. E-mail: \\ K.I.Gidado@brighton.ac.uk \\ ${ }^{3}$ School of Environment and Technology, University of Brighton, United Kingdom.
}

Project Management

Received November 8, 2017; received revision January 8, 2018; accepted January 9, 2018

Available online January 10, 2018

\begin{abstract}
In crowded large space buildings, safety is one of the most important concerns for facilities managers. Within the built environment, safety has been classified into two main parts: objective safety (normative and substantive) and subjective safety (perceived). A lot of emphasis has been given to objective safety, but research has shown that subjective safety could be equally important and cannot be overlooked. A flow of risk factors within crowded large space buildings such as sports stadiums, concert halls, and religious buildings have resulted in crowd disasters in various venues across the world. Every user in such facilities during mass gathering can be exposed to safety risks, which can be mitigated by using effective risk management as a component of facilities management. This paper focused on subjective safety and aimed to validate the measurement model of latent constructs measuring 12 risk constructs of perceived safety in crowded large space buildings. Two theoretical frameworks (FIST and Six dimensions and loci of crowd disaster) and other relevant literature were used to generate items for the respective constructs. The research chose to use the Holy Mosque in Makkah as a case study (crowded large space building), which is 356,800 square metres with a maximum capacity of two million users (pilgrims). Data was collected using iPad devices via a group-administered questionnaire distributed to 1,940 pilgrims across 62 different nationalities. The data wasanalysed using the Statistical Packages for the Social Sciences (SPSS) and Analysis of Moment Structure (AMOS) for descriptive analysis and Confirmatory Factor Analysis (CFA) respectively. CFA has validated the measurement model of the 12 constructs for unidimensionality, validity, and reliability.
\end{abstract}

Keywords: Facilities management, risk management, crowd safety, confirmatory factor analysis.

\section{Introduction}

The fundamental principle of safety in the built environment is to ensure that the occupants of a building are safe during normal conditions and emergency events(Sagun et al., 2008)."It is the activity that seeks to minimize or eliminate hazardous conditions that can cause bodily injury" (Chinda, 2011).Safety in the built environment has been classified into objective safety and subjective safety (perceived safety) (Sorensen and Mosslemi, 2009). In an organizational context, objective safety is measured as the actual number of or the risk of incidents or injuries occurring. Subjective safety is intangible and refers to the feeling or perception of being safe or unsafe within a specified period. Numerous studies have been undertaken on objective safety in the built environment (Wieringa et al., 2016,(Nicholson and Roebuck, 1995; Helbing and Mukerji, 2012; Still, 2000) but there has been a lack of research on subjective safety (perceived safety) particularly in crowded large space buildings where large numbers of users attend an event.
Moller et al. (2006) highlighted that safety is the inverse of risk; the lower the risk the higher is the safety. This implies that safety can be achieved through identifying and mitigating the risk to a tolerable level by using effective risk management approaches. Leopkey and Parent (2009) defined risk management as a proactive approach to eliminating threats to an organization through anticipating, identifying, assessing and mitigating the possible risks. The British Institute of Facilities Management (BIFM, 2014) have classified risk management as one of the 24 key components of Facilities Management (FM). FM covers all aspects of planning, managing space, designing, environmental control, health and safety and support services. It significantly contributes to the delivery of strategic and operational objectives on a day-to-day basis. When events are held in large buildings, Ali et al. (2011) highlighted that facilities managers must be involved before, during and after the event to reduce risk and enhance safety. Booty (2009) stated that each large building used by large 
numbers of users (crowd) normally has diverse types and levels of risk. According to Alnabulsi and Drury (2014), crowd safety is a major concern to the users and the management of crowded large space buildings. In the past decades, there have been numerous crowd disasters in diverse venues all over the world. The Center for Research on the Epidemiology of Disasters (CRED) (2003) has determined a criteria for an accident to be considered a disaster only when at least one of the following must be fulfilled: 10 or more people killed; 100 or more people get injured; declaration of a state of emergency; a call for international assistance. Some of the major crowd disasters were reviewed that occurred in Sunderland (1883, deaths183), London (1943, 173 deaths), Bolton (1946, 33 deaths), Glasgow (1971, 66 deaths) and Sheffield (1989, 96 deaths). Dickie (1995) confirmed that a flaw in management of the risk factors in the facility was one of the main reasons for these disasters.

This paper has identified and validated 12 risk constructs of perceived safety and generated 41 items (indicators) that can help the facilities managers and clients (those who are in charge) to reduce the potentiality of safety risks in crowded large space buildings. Two theoretical frameworks (FIST and Six dimensions and loci of crowd disaster) and other relevant literature were used to generate the items for the respective constructs which will be discussed in more details in section 2 .

\section{Risk Constructs of Subjective (Perceived) Safety in Crowded Large Space Buildings}

In large space buildings with an excessively large number of people gathering in a specified area such as sports stadiums, concert halls, and religious buildings there might be greater risks to their safety (HSE, 2000). Several risk factors have been proposed by numerous researchers that may threaten people's life. Fruin (1993) proposed 4 key risk factors derived from his personal experiences, analysis of major crowd incidents and traffic flow principles. He used the acronym FIST for the 4 factors defined as Force (F), Information (I), Space (S) and Time (T). Lately in 2014, Chukwuma and Kingsley (2014) suggested six dimensions and loci of crowd disaster involving: Stampede, Riot, Structural and Mechanical failure, Terrorist attacks, Explosion (fire, chemical) and Natural disaster. In addition, six causes and triggers for crowd disasters were reported by National Disaster Management Authority (NDMA) (2014), which was compiled from public inquiry reports, namely: Structural, Fire/Electricity, Crowd Control, Crowd Behaviour, Security, and Lack of coordination between various stakeholders. It has been found that the psychological factors have given a less attention by the researchers. Sime (1995), argued that "psychological factors need close attention to human movement and hazard growth predictions". The report of the Royal Society (1992), stressed the need to integrate engineering approaches to the estimation of engineering risk with a social science approach, in which risk perception by the public and management is considered to be as important as safety engineering criteria". It has been shown that perceived safety is significant in an effort to understand people behavior and improve safety (Zhuang and $\mathrm{Wu}, 2012$ ).It can be concluded that all of these factors can be risky and must be considered by those who are managing crowded large space buildings.
From the above review, it has been established that all the theoretical frameworks were proposed based on the qualitative approaches: semi-interview, reviewing public inquiry reports, analysis of major incidents and traffic flow principles and to date, these factors have not been validated statistically or empirically. The subjective safety has been overlooked by the researchers who focused more on the objective safety. From the existing theoretical frameworks, comprehensive critical risk constructs were produced to validate the measurement model of latent constructs and test the constructs empirically. These risk constructs are: Perceived Force, Perceived Poor Information, Perceived Insufficient Space, Perceived Poor Real Time Management, Perceived risk of Stampede, Perceived risk of Riot, Perceived risk of Structural Failure, Perceived risk of Terrorist Attack, Perceived risk of Explosion and Perceived risk of Natural Disaster, Perceived Safety and User Behaviour. A word perceived has been added since the focus is to measure the subjective safety (perceived) which as stated earlier is intangible and refers to the feeling or perception of being safe or unsafe within a specified period.

The purpose of the following subsections is to generate items (indicators) from the relevant literature to measure each risk constructs that will enable the research to measure the subjective safety in crowded large space buildings.

\subsection{Crowd (Users) Behaviour (UB)}

Raineri (2015), claimed that insufficient attention to the behaviour of the people in crowded large space buildings is major factors in crowd disasters. Crowd behaviour refers to the way in which persons act or behave towards others. Le Bon (1896), argued that the people among the crowd lose all feeling of self-responsibility, and become subject to contagion. Le Bon believed that whoever of the people be in the crowd, they can be transformed, changed from rational, thoughtful individuals into irrational and extreme followers. In addition, "law of the mental unity of crowds" crowd behaviour, people act as the collective mind which viewed as a type of diseases that infected and spread from group to another and then to the rest of the crowd. Floyd Allport rejected the idea of a group mind, suggesting that the crowd is made up of individuals having similar behaviors and the concept of mind could not be separated from an individual. Allport (1924), states that "the individual in the crowd behaves just as he would behave alone only more so". Berlonghi (1995) pointed out to the importance of understanding the deindividuation, once people lose their self-awareness and abandon their normal control, people become more controlled by the situation rather than the self. Several studies have shown that the behaviour of the people can be influenced by a large crowd with high density (Oakes and North, 2008; Westover, 1981). Berlonghi (1995) suggested important factors that can influence crowd behaviours that play an important role in design, management and crowd control. These factors include location and time of the event, size of the crowd, crowd mobility, demographics of the crowd (e.g. age, gender), schedule of event activities, crowd movement models, the geometry of the location, weather conditions and density of crowd in different areas. Some of the researchers believe that crowd causes stress and anxiety that may lead people tolosetheir control and their abilities will decline significantly(Taylor et al., 1990; Hoseini et al., 2011).At some events, the crowd can turn 
into a mob and become aggressive. "The aggressive behaviour may be in response to such strictures or emotional triggers such as elation, fear, or anger, and may be exaggerated by impairments such as drug or alcohol intoxication and lack of accurate information. Aggressive behavior may also result from physical discomfort due to environmental conditions such as heat, cold, noise, etc., and may become more likely if others are displaying aggressive behavior and are either rewarded or go unpunished" (Silvers, 2008).Psychological experiments have shown that when people get a high level of arousal, responsibility is diffused, people may act irrationally and not be able to control their own behaviour(Berlonghi, 1995). Those people may start throwing objects, screaming and pushing people while some may turn into mobs carrying out theft, vandalism, rioting, group violence leading to a potential crowd disaster (Myers, 1990).

Based on the above literature review, the items or indicators of the UB variable include: bad behaviour (abnormal actions such as people move in opposite direction, sitting on the way), lose self-control, cognitive anxiety, stress due to other external factors, and deliberate aggressive action.

\subsection{Perceived Safety (PS)}

Perceived safety refers to the feeling (or perception) of an unsafe situation that exists during an event. Feeling unsafe during an event can drive people to panic from real or perceived risk through acting unusually such as pushing and shoving (Challenger et al., 2009b). Studies in urban design have identified several factors that may have an influence on perceived safety including characteristics of the environment, the physical condition, and the configuration of spaces (Mehta, 2013). This perception could differ from one person to another, for instance, women and older people have a more diverse sense of safety compared with others. Crowd studies have found that the perceived crowding, which is defined by Kim et al. (2016) as "the psychological counterpart to population density", is closely tied to perceived safety (Graefe et al., 1984; Dawson and Watson, 2000). Other researchers such as Tseng et al. (2009) have stated that there is a negative correlation between perceived safety and perceptions of crowding i.e. people's sense of safety declines to the level of perceiving the risk of fatality as perceptions of crowding increase. Heavy crowding may raise the user's perception of risk of trampling or stampede. Similarly, where the physical condition of the facility is of low quality, this will raise the risk of falls, slips, and trips that can affect the user's perception of safety. Again, someone new to an environment may find it safe because they may not be familiar with specific cues of the context. Another condition is the users' awareness or experience of any structural or mechanical or electrical damage to existing facilities or the potentiality of occurrence of such damage may raise the perception of risk of facilities failure or damage. From this literature review, it could be concluded that the items or indicators for the PS variable should include: perceived risk of fatalities; perceived risk of failure of structure or artificial services; perceived risk of falls, slips and trips; perceived risk of trampling or stampede; the feeling of unsafe; overcrowding; perceived risk of injuries; simply poor safety.

\subsection{Perceived Force (PF)}

Perceived force refers to the feeling of the individual while within a crowd that may be produced by either hearing, seeing or sensing force. The force may reach such a high level that it cannot be controlled or resisted because of crowd pressure. It has been emphasized that crowd compression, compressive asphyxia and a subsequent loss of footing or inability to move are the main reasons of deaths during an event (Silvers, 2008; Still, 2016; Fruin, 1993; Yokota, 2005). Berlonghi (1995) claims that serious injuries and fatalities may occur from suffocation when people in a crowd are being swept along with movement and compression. Research has shown that the forces that can be created when density exceeds a certain level may lead to a serious incident. From this review, the items or indicators for PF variable could be considered as breathing difficulty; crowd pushing; movement difficulties; crowd pressure; uncontrollable pushing; and suffocation.

\subsection{Perceived Poor Information (PPI)}

In large space buildings, it is crucial for the users to obtain real time information about the crowd condition including crowd actions and reactions, whether real or perceived. Information communicated to - or withheld from - the crowd can influence their perceived safety. The Challenger et al. (2009b) states that "communicating with the crowd is essential in maintaining order and managing behaviour". The communication includes information to and fro flow using oral or signs and sign ages.Sime (1999) stressed that poor health and safety information prior to or during an event has led to many crowd incidents. The information comprises all means of communication such as signs and announcements. Fruin (1993) suggests that actions and training of personnel, sights and sounds all affect group perceptions. Setting up of a communication centre and a robust centralized crowd management system is good practice. Experts have highlighted that real-time information and communication are significant factors in minimizing the risk of crowd disasters. From the above review, the items or indicators for the PPI variable could be health and safety information; communication system; availability of all types of signs; the visibility of the installed signs; and warning signs.

\subsection{Perceived Insufficient Space (PIS)}

Still (2000), argued that insufficient or poor use of space is considered a key risk factor in crowded large space buildings. Fruin (1993) claimed that architects and engineers typically pay minimal attention to planning people's movement and perceptions, but greater emphasis to meeting the local building codes regarding space for key functions such as receptions, standing areas, seating areas, corridors, conveniences, stairs, escalators, and lifts. Research has shown that crowding can take place not only at the main event space but also at entrances, exits, walkways, stairs, and lifts. It has been shown that human psychology usually undergoes a change when the capacity becomes high and the venue does not have enough space to accommodate the crowd. Generally, when the individuals within a crowd perceive risk or a possible disaster, they panic and move to an exit ignoring alternative exits made available. Fruin (1993) stated that within a high-density crowd, it is difficult to describe the psychological and physiological pressures, which leads to individuals losing self-control. Several studies have emphasized that crowd density has an effect on perceived safety and on people's behaviour(Oakes and North, 2008; Westover, 1981; Alnabulsi and Drury, 2014). The above 
review suggests that the indicators or items for PIS could be summarised as densities of activities areas; availability of stairs, lifts, and escalators; densities at entrances and exits; densities at walkways; and space available for the main event.

\subsection{Perceived Poor Real Time Management (PPRTM)}

Fruin (1993) has established that poor real time information for proactive intervention is a key risk factor in crowded large space buildings. This relies on an effective control system that detects, analyse and intervene proactively.Lloyd et al. (2017) stated that failure to detect the behavior of the crowd at the right time can lead to serious incidents. Time plays an important role, for example, the inflow of the pedestrian compared to the rapid egress which is much less while the pedestrians are leaving an event. It has been emphasized that the flow of the pedestrians must not exceed the capacity of the spaces available (Mehta, 2013; Yang and Wyckoff, 2010). UK Cabinet Office guidance (2009) has indicated that lack of consideration is sometimes given to how crowd flow and density can be successfully managed by controlling timings that can avoid waiting and unnecessary congregation in and around the building. The items or indicators for PPRTM could be summarised as: crowd flow control; availability of timely information and intervention; waiting time for services; waiting time at entrances; robust control system set up.

\subsection{Perceived Risk of Stampede (PRS)}

Human stampede is a phenomenon that has occurred many times around the world. It refers to the hazard that can take place during large events where people gather (Illiyas et al., 2013). Two forms of stampede have been identified: that which happens if people panic when attempting to escape from danger; whereas the second form occurs when people rush toward something needed or desired at the event (Burkle and Hsu, 2011). Based on previous studies, human stampede has been associated with grave consequences such as loss of life, serious injury, property damage, psychological trauma and distress (Chukwuma and Kingsley, 2014). Stampede can occur in many types of large gatherings including political rallies, social events (funerals, music events, shop sales etc.), sporting events (soccer matches, athletic competitions, etc.), religious events (pilgrimages, etc.), job selection screening or test exercises, emergency situations (terrorist group) or natural disaster (Floods, earthquakes, hurricane, etc.) (Illiyas et al., 2013; Helbing and Mukerji, 2012; Still, 2016). These studies have reported that religious events have seen the worst incidents of a human stampede with most incidents occurring in developing countries such as India and Saudi Arabia. Pushing, trampling, and crushing is associated with human stampede. Research has shown that when persons in a crowd chose to create separate groupings and decide to insist on moving collectively together could lead to pushing and crushing within the crowd. It is also noticed that blockage of stairs, pathways, and escalators leads to stampede or trampling in large space buildings. This could be caused by wheelchairs or other obstructions brought in by the users. According to Chukwuma and Kingsley (2014), thehuman stampede is a typical instance of crowd disaster. Sociological theorists have stressed that individuals lose their sense of responsibility during a stampede situation (Miller, 2015). Studies on crowd disaster (e.g. Still, 2000) claim that when the crowds need to turn in order to change the direction (e.g. in corners and stairwells), there is a risk of trampling and/or stampede to occur. They further state that when such restricted passage has sudden changes in the escape direction, it could also trigger trampling and stampede as people rush to flee (Shiwakoti and Sarvi, 2013). The key items or indicators for PRS variable could be summarised as rushing; blockage of exits and stairways; movement in opposite direction; blockage of pathways with objects such as wheelchairs.

\subsection{Perceived Risk of Riot (PRR)}

Riot is a risky phenomenon, with many possible causes of incidents (Torrens and McDaniel, 2012). The National Disaster Management Authority of India (2014) defined riot as "a form of civil disorder characterized often by what is thought of as disorganized groups lashing out in a sudden and intense rash of violence against authority, property or people". This has frequently occurred in different parts of the world. One example of a riot occurred in 1992 in Los Angeles that resulted in 52 people dead and 2500 injured as well as at least \$446 million property damaged(DiPasquale and Glaeser, 1996).Riots are often aggressive and violent, they usually start peacefully and then transform into a violent mob (O'Connell, 2009). Once they start, it is likely impossible to control them (Torrens and McDaniel, 2012). In large space buildings, riots in a crowd are normally caused by the interaction between safety/security staff and users, or between the users. The items for the PRR variable could therefore be summarised as: users aggression towards authority; safety/security staff acting aggressively towards users; and users acting aggressively towards each other.

\subsection{Perceived risk of Structural Failure (PRSF)}

The failure of any temporary or permanent structure in a crowded venue can have an overwhelming effect (Goldblatt, 1996). Dickie (1995) indicated that structural failure or power cuts or failure of hard services such as ventilation and air-conditioning is not uncommon. In many buildings and events across the world, insufficient design, poor construction, inadequate codes of practice and overloading have all caused significant failures (Petroski, 1992). According to the National Disaster Management Authority of India (NDMA) (2014), structural failures have also been cited as reason for crowd disasters on numerous occasions. The indicators or items for PRSF could therefore be identified as: failure of ventilation system; power cuts; fall or collapse of parts of structure; overload of installed facilities.

\subsection{Perceived Risk of Terrorist Attack (PRTA)}

In recent decades, terrorism has been increasing worldwide. Most studies on terrorism have lacked theoretical and empirical analysis (Silke, 2001; Lum et al., 2006). Furthermore, accepted definitions of terrorism are unclear but several elements are shared in common. These common elements refer to the violence or threat of actions that result in fatalities and serious injuries. Although many terrorist attacks seem irrational, these are always well planned and executed. According to the current definition of the U.S. Department of Defense (US DoD, 2015): terrorism is "the unlawful use of violence or threat of violence, often motivated by religious, political, or other ideological beliefs, to instill fear and coerce governments or societies in pursuit of goals that are usually political." A further definition is given by Tilly (2004), who described 
terror as "political strategy" which is the "asymmetrical deployment of threats and violence against enemies using means that fall outside the forms of political struggle routinely operating within some current regime". The Oxford English Dictionary defines terror as "the state of being terrified or greatly frightened; intense fear, fright or dread'. Nowadays, terrorism has become one of the main risk dimensions which requires a comprehensive safety management. It is a veritable threat which targets public venues particularly, crowded places including sports and religious events. In a large space building, the users' perception of safety with regard to a terrorist attack happening could be influenced by the placement of security personnel that are visible to the crowd. As the user enters the building and experiences a robust security check, the perception of safety inside the venue could be enhanced. Similarly, perception could be influenced by the degree of confidence the user has on the modern systems of security used at the venue. The items or indicators of PRTA are summarised as: poor security checks at entrances; absence of security at courtyards; absence of security at activities areas; and poor use of modern security systems.

\subsection{Perceived Risk of Explosion (Fire/Chemical) (PRE)}

The International Labour Office (ILO) (1988) defined major accident as "an occurrence such as a major emission, fire or explosion resulting from uncontrolled developments in the course of an industrial activity, leading to a serious danger to man, immediate or delayed, inside or outside the establishment, and to the environment, and involving one or more dangerous substances". According to Shaluf (2008), fire and explosion are major accidents which are classified as a technological disaster. Many technological disasters have occurred around the world, such as the fire that swept through a tent in Mina, Makkah during Hajj in 1997; the Gothenburg, Sweden, Disco in 1998; the Rhode Island Rock concert in 2003 (Still, 2016). Sime (1999) reviewed a number of disaster cases with respect to fire and behavior of the people within the fire situation. These disasters included the Beverly Hills Supper Club in 1977; Summerland Woolworth's in 1937; Bradford King's Cross in 1985 (J.D.Sime, 1995; David V. Canter, Miriam Comber, 1989; Richard L. Best, 1978). In the cases studied, it is the fire that made people to panic in response to save their lives, and it has been established that it is the panic that resulted in the fatalities experienced. For example, due to the behavior of the people who panicked at the Beverly Hills Supper Club event in Kentucky, the USA in 1977, 300 people were stampeded. In a large space building, fire or explosion can create panic, and the users' perception of safety could be influenced by its occurrence. In some instances, the visible provision of safety systems that could be used to control the effect of the explosion or fire could improve safety perception. The items or indicators to PRE are, therefore: explosion or fire due to electrical cables; explosion or fire due to an overload of services; poor firefighting systems.

\subsection{Perceived risk of Natural Disaster (PRND)}

Natural disasters are catastrophic events which occur due to natural forces and are not controllable by mankind. Examples include flood, climate change (heat waves or cold waves), strong wind, volcanic eruptions, tornados, earthquakes, etc. (Shaluf and Ahmadun, 2006). In the last few decades, natural disasters have increased worldwide, particularly in the developing countries. According to Riebau and Qu (2005), natural disasters present a serious risk and result in heavy loss of life and property damage. They pointed out that "floods are among the greatest natural disasters known to mankind". Based on Shaluf (2007), Asia and the Pacific are the regions most exposed to natural disasters. Shaluf and Ahmadun (2006) showed that most natural disasters result from heavy rains. Another natural disaster threat comes from climate change. Several studies have shown the significant association between climate change (e.g. high temperature) and mortality (Dear and Wang, 2015; Patz et al., 2000). Based on the Intergovernmental Panel on Climate Change7 report in 2014, the increase of heat and decrease of cold due to climate change will result in increase of mortality in some parts of the world (Dear and Wang, 2015). For example, in the summer of 2003 it was reported that 70,000 Europeans died due to heat waves (Robine et al., 2008). It is expected that the intensity of heat waves and the average of global temperatures will be increased as a result of climate change (The Regional Office for Europe of the World Health Organization, 2011). Numerous studies have discovered that exposure to heat waves may cause cramps, fluid loss, fainting, heat exhaustion, dehydration, heat stress, heat stroke and ultimately mortality(The Regional Office for Europe of the World Health Organization, 2011; Lowe et al., 2011; Kalkstein and Greene, 1997). Within a short time of exposure to high temperatures, people affected by heat may suffer fatalities (Diaz et al., 2006). The elderly (aged 60 years or older), particularly women, and those with chronic lung diseases are more affected (Lowe et al., 2011). High temperatures are likely to affect people physically and psychologically. In events held in large space buildings, natural disasters such as flood and volcanic eruptions could be discarded, but heat/cold waves and rains are important. Anderson (2001)underlined that hot temperatures can increase aggressive behavior by directly increasing feelings of hostility and indirectly increase aggressive thoughts. This could be worse within large gathering events including sport, religious and political events. It is therefore identified that the items or indicators for PRND are: sunstrokes; lack of shading; high temperatures; heat exhaustion; and lack of good drainage and slippery surfaces.

\section{Method}

This paper adopts postpositivism, a paradigm which is more related to quantitative (experiment, survey) approach than qualitative (interview, observation) approach. It is a research paradigm that refers to a philosophical framework that guides how scientific research should be conducted based on people's philosophies and their assumptions about the world and the nature of knowledge(Creswell, 2014). Although the researchers' personal experiences and knowledge of the problem situation helped, the research primarily employed a survey (questionnaire) as a technique for data collection.

The research chose to use the Holy Mosque Building, (situated at Makkah) as a crowded large space building to test and measure the validity and reliability of the constructs and items. The Holy Mosque is the largest mosque in the world, at approximately 356,800 square meters (Alnabulsiand Drury, 2014). It can accommodate around 1.2 million worshipers at the same time. The aerial photograph of the Holy Mosque is shown in Fig. 1 
showing the open centre where the anticlockwise circumvallation (around a cube small building called the Kaaba) called the Tawaf is carried out, and where the longitudinal walking to and from between two points called Safa and Marwa.

The Hajj is an annual journey to Makkah that is undertaken by Muslims as one of the compulsory acts of worship in the religion of Islam. It is one of the largest events having persons with different cultures, ages, genders, nationalities, and languages. The Hajj is a requirement for every Muslim who is physically and financially capable of undertaking the journey at least once in his/her lifetime. It takes place once a year in a period ranging between 4 to 6 days. The person that performs the Hajj is regarded as a Pilgrim. Whilst in Makkah, the pilgrim is required to visit four holy places: the Holy Mosque, the Mina, Muzdalifah, and Arafat (Alsolami et al., 2016). These are situated in different parts of the city and its neighbourhood (Ascoura, 2013). Every pilgrim visits the Holy Mosque at least thrice by with the middle visit occurring on the same day for all pilgrims (it is often at this time that the crowd capacity is at its peak). The Holy Mosque during Hajj event has unique characteristics that facilitate an in-depth understanding of risk factors that may lead to crowd disasters.

The research adopted the Stratified random sampling, which is a probability sampling in which the population firstly needs to be separated into homogenous segments (strata) according to a certain characteristic of the population, and then from each segment (strata), a simple random sample can be selected. These selected samples from the various segments (stratum) are then combined and arranged into a single sample (Daniel, 2011). This approach uses the available information of the population (e.g. total population, nationalities) prior to selecting the sampling to make the sampling more efficient (Schutt, 2006). This enabled the research to select pilgrims (samples) from numerous countries. After a robust risk and ethical assessments that ensure that the research conforms to good practice, 1,940 pilgrims (both local and foreign) were surveyed within the zone of Makkah during the Hajj of the year 2016 (1437 Arabic Calendar).

The questionnaire covered thirteen sections: section one is background demographic data and information about the respondents, and sections two to thirteen are designed to test the variables to perceived crowd safety. The items included in the questionnaire were adapted from the literature review in Section 2 particularly from Berlonghi, 1995; Alnabulsiand Drury, 2014; Fruin, 1993; Chukwumaand Kingsley, 2014; Kemp and Moore, 2010; Rahmt et al., 2011; Illiyas et al., 2013 among others. All the items were measured using a 5-point Likert scale $(1=$ strongly disagree to $5=$ strongly agree, or $1=$ never occur to $5=$ almost always occurs). Several items were modified to attain the aim of the research.

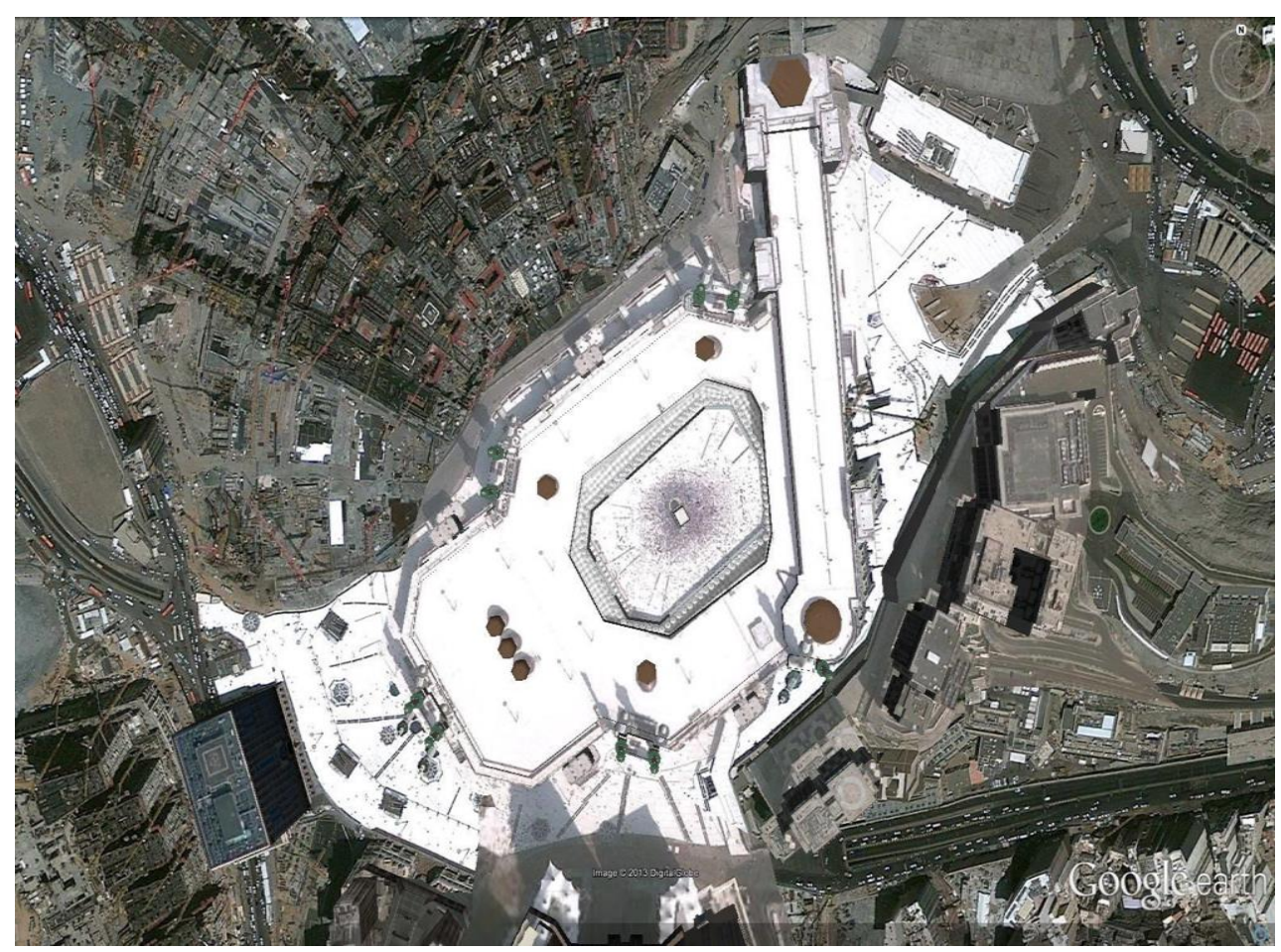

Fig. 1. The aerial photo of the Holy Mosque 


\section{Results and Discussion}

The data wereanalysed using the Statistical Packages for the Social Sciences (SPSS) and Analysis of Moment Structure (AMOS) for Descriptive Analysis (DA) and Confirmatory Factor Analysis (CFA) respectively.

The descriptive statistics is the best strategy for providing summary of the data and describing the sample. Table 1 reports summary of the demographics data for the 1940 respondents. This descriptive statistics cannot provide information for causal analysis (Choi, 2013), CFA is therefore used for the causal analysis for this study. The researcher determines the number of factors that exist and which variables belong to which factors or construct before the results can be computed. This statistical technique does not specify variables to factors instead the factors are determined by the researcher based on the theory being tested prior to any results being obtained. It is applied to test the theoretical pattern of the variables loading on specific constructs and to show how well the theoretical specification of the factors can match the reality (the actual data). CFA enables the research to accept or reject the theory that has been studied (Hair et al., 2010).

\subsection{Confirmatory Factor Analysis (CFA) before Constraints}

When undertaking a CFA, it is necessary to assess the unidimensionality, convergent and discriminant validity, as well as reliability (Awang, 2015). The CFA has to be performed for all latent constructs prior to modeling the interrelationship in Structural Equation Modeling (SEM). The unidimensionality should be made first before assessing the convergent and discriminant validity, and reliability. Unidimensionality refers to the measurement items that have an acceptable factor loading for the latent construct which is 0.60 and above ( $\mathrm{Hu}$ andBentler, 1999; Awang, 2015).

The CFA results as shown in Fig. 2. presents 12 latent constructs that includes Perceived Force (PF), Perceived Poor Information (PPI), Perceived Insufficient Space (PIS), Perceived Poor Real Time Management (PPRTM), Perceived risk of Stampede (PRS), Perceived risk of Riot (PRR), Perceived risk of Structural Failure (PRSF), Perceived risk of Terrorist Attack (PRTA), Perceived risk of Explosion (fire/chemical) (PRE), Perceived risk of Natural Disaster (PRND), Crowd (Users) Behaviour (UB) and Perceived Safety (PS). Each latent construct has 3 to 8 number of items, with a grand total of 59 different items.

Majority of the factors loading for each item in Fig. 3 have achieved the recommended value which is 0.60 as stated earlier. The results revealed that several items are below 0.60 which must be deleted before proceeding to the next analysis. (Awang, 2015) argued that "in order to ensure unidimensionality of a measurement model, any item with a low factor loading less than 0.60 should be deleted".

\section{Convergent Validity}

To establish convergent validity, the model fit must be adequate, and the average variance extracted (AVE) must exceed 0.50 (Hair et al., 2010). AVE verifies whether answers from different respondents to question-statements are sufficiently correlated with the respective latent variables. For acceptable model fit (Hu and Bentler, 1999; Awang, 2015; Gaskin and Lim, 2016) recommend a comparative fit index $(\mathrm{CFI}) \geq 0.90$, standardized root mean square residual $(\mathrm{SRMR}) \leq 0.08$, and root mean square error of approximation $(\mathrm{RMSEA}) \leq 0.06$.

Table 2 provides the results of the model fit measures. The values included in the Table indicate that the model is not fit because the measures of CFI $=0.813$, SRMR $=$ 0.100 , and RMSEA $=0.065$ have not achieved the required level. The CFA results confirm that the model is not accepted for further analysis.

In terms of the results of AVE for all constructs as illustrated in Table 4 also have not achieved the standard minimum required level of 0.50 .

\section{Discriminant Validity}

To establish discriminant validity three criteria must be met (Gaskin, 2016a; Hair et al., 2010). The FornellLarcker test needs the square root AVE for each construct to be greater than any inter-construct correlations (Fornell and Larcker, 1981). The constructs for this test have not met this criterion. The square root of the AVE of the constructs is less than their estimates of correlation as presented in Table 3.

The other two criteria for discriminant validity that must also be met are the Maximum Shared Squared Variance (MSV) and Average Shared Squared Variance (ASV).Hair et al., (2010) recommend that MSV and ASV must be less than the results of AVE (MSV<AVE, ASV< AVE). The results of ASV and MSV as detailed in Table 5 indicate that the measurement model is not valid.

\section{Reliability and Construct Validity}

Table 4 presents the results of the reliability and construct validity test. Two reliability tests have been undertaken for this study: composite reliability (CR) and Cronbach's alpha. This study has used both tests to guarantee the reliability of the data before conducting any further analysis. Chin et al. (2003) claimed that CR is more accurate than Cronbach's alpha because it does not assume that the loadings or error terms of the items are equal. Both tests CR and Cronbach's Alpha have met the standard minimum threshold of 0.60 and 0.70 respectively (Gaskin, 2016b; Peterson and Peterson, 1994).

In terms of convergent and discriminant validity and reliability of results, the measures as shown in the Tables 2, 3 and 4 indicate that the convergent and discriminant validity did not meet the required level. In contrast, the result of the CR and Cronbach's alpha have exceeded the required level of 0.60 and 0.70 confirming the reliability of the model.

Overall, the result of the model measurement did not show a solid evidence of unidimensionality, convergent and discriminant validity. Therefore, according to (Awang et al., 2015), the Modification Indices (MI) should be checked in order to obtain a good model fit. When MI is over 15 it should be considered as a high multi-collinearity problem. To solve the problem, it is recommended to delete either one of factor loadings or covarying error terms and to run the model obtaining the new measurement model. 
Table 1. Demographics of the respondents

\begin{tabular}{|c|c|c|c|c|c|c|}
\hline \multicolumn{2}{|c|}{ Demographic information } & Frequency & Percentage & Mean & Maximum & Minimum \\
\hline \multicolumn{2}{|l|}{ Age } & & & 42.44 & 60.00 & 21.00 \\
\hline \multirow[t]{2}{*}{ Gender } & Male & 1916 & $98.8 \%$ & & & \\
\hline & Female & 24 & $1.2 \%$ & & & \\
\hline \multirow[t]{4}{*}{ Education } & Cannot Read or Write & 490 & $25.3 \%$ & & & \\
\hline & Middle/High School & 684 & $35.3 \%$ & & & \\
\hline & Bachelor & 625 & $32.2 \%$ & & & \\
\hline & Master or PhD & 141 & $7.3 \%$ & & & \\
\hline \multirow[t]{3}{*}{ Tawaf Group } & Individually & 419 & $21.6 \%$ & & & \\
\hline & With Family & 801 & $41.3 \%$ & & & \\
\hline & With Group & 720 & $37.1 \%$ & & & \\
\hline
\end{tabular}

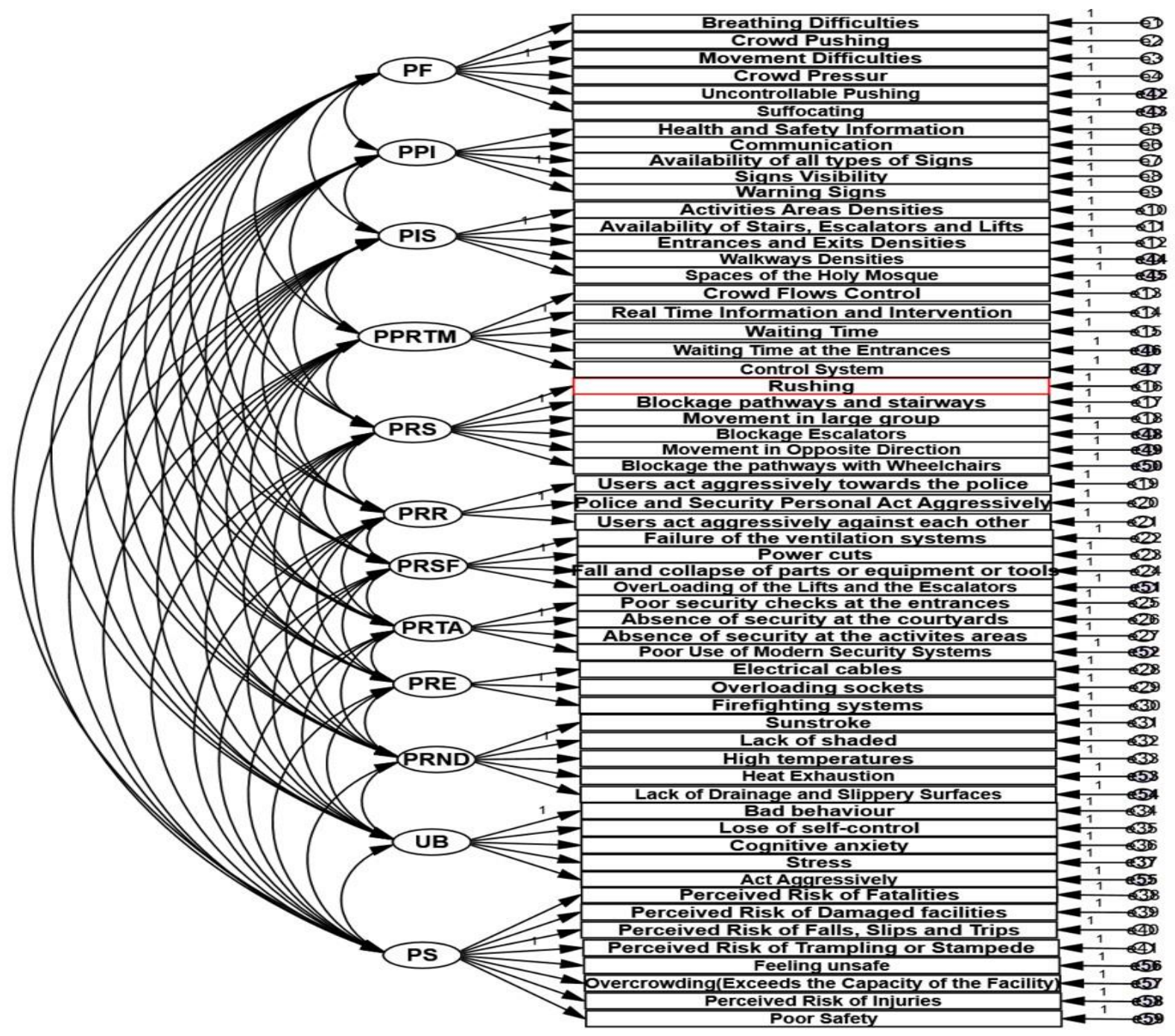

Fig. 2. Confirmatory Factor Analysis (CFA) for all constructs before constraints 
Table 2. Model fit measures before constraints

\begin{tabular}{cccc}
\hline Measure & Estimate & Threshold & Interpretation \\
\hline CFI & 0.813 & $>0.95$ & Bad fit \\
SRMR & 0.100 & $<0.08$ & Acceptable \\
RMSEA & 0.065 & $<0.06$ & Acceptable \\
\hline
\end{tabular}

Table 3. Discriminant validity Fornell-Larcker test

\begin{tabular}{|c|c|c|c|c|c|c|c|c|c|c|c|c|}
\hline Construct & PRF & PRPI & PRIS & PRPRTM & PRS & PRR & PRSF & PRTA & PRE & PRND & UB & PS \\
\hline PRF & 0.785 & & & & & & & & & & & \\
\hline PRPI & 0.706 & 0.839 & & & & & & & & & & \\
\hline PRIS & 0.738 & 0.658 & 0.753 & & & & & & & & & \\
\hline PRPRTM & 0.78 & 0.785 & 0.804 & 0.756 & & & & & & & & \\
\hline PRS & 0.713 & 0.566 & 0.627 & 0.732 & 0.585 & & & & & & & \\
\hline PRR & 0.621 & 0.602 & 0.591 & 0.695 & 0.73 & 0.766 & & & & & & \\
\hline PRSF & 0.428 & 0.285 & 0.348 & 0.358 & 0.176 & 0.373 & 0.661 & & & & & \\
\hline PRTA & 0.606 & 0.587 & 0.578 & 0.604 & 0.48 & 0.55 & 0.485 & 0.77 & & & & \\
\hline PRE & 0.477 & 0.477 & 0.447 & 0.455 & 0.337 & 0.51 & 0.364 & 0.683 & 0.755 & & & \\
\hline PRND & 0.242 & 0.332 & 0.322 & 0.352 & 0.329 & 0.286 & -0.159 & 0.041 & 0.019 & 0.637 & & \\
\hline UB & 0.775 & 0.649 & 0.701 & 0.75 & 0.731 & 0.718 & 0.345 & 0.582 & 0.512 & 0.35 & 0.718 & \\
\hline PS & 0.609 & 0.603 & 0.501 & 0.651 & 0.577 & 0.656 & 0.351 & 0.708 & 0.64 & 0.183 & 0.725 & 0.625 \\
\hline
\end{tabular}

\begin{tabular}{|c|c|c|c|c|c|c|c|}
\hline Constructs & $\begin{array}{l}\text { Cronbach } \\
\text { (above 0.7) }\end{array}$ & $\begin{array}{c}\text { CR (above } \\
0.60)\end{array}$ & $\begin{array}{c}\text { AVE } \\
\text { (above } \\
0.50 \text { ) }\end{array}$ & MSV & ASV & $\begin{array}{c}\begin{array}{c}\text { Convergent } \\
\text { validity }\end{array} \\
\text { CR > AVE } \\
\text { AVE > } 0.50\end{array}$ & $\begin{array}{c}\begin{array}{c}\text { Discriminant } \\
\text { validity }\end{array} \\
\text { MSV }<\text { AVE } \\
\text { ASV }<\text { AVE }\end{array}$ \\
\hline $\mathrm{PF}$ & 0.907 & 0.906 & 0.616 & 0.608 & 0.40 & Yes & Yes \\
\hline PPI & 0.922 & 0.922 & 0.703 & 0.616 & 0.34 & Yes & Yes \\
\hline PIS & 0.866 & 0.865 & 0.566 & 0.647 & 0.35 & Yes & No \\
\hline RPRTM & 0.858 & 0.865 & 0.571 & 0.647 & 0.43 & Yes & No \\
\hline PRS & 0.740 & 0.75 & 0.342 & 0.536 & 0.33 & No & No \\
\hline PRR & 0.804 & 0.81 & 0.587 & 0.533 & 0.35 & Yes & Yes \\
\hline PRSF & 0.713 & 0.746 & 0.437 & 0.235 & 0.12 & No & Yes \\
\hline PRTA & 0.843 & 0.853 & 0.592 & 0.502 & 0.32 & Yes & Yes \\
\hline PRE & 0.780 & 0.798 & 0.570 & 0.466 & 0.23 & Yes & Yes \\
\hline PRND & 0.744 & 0.764 & 0.405 & 0.124 & 0.07 & No & Yes \\
\hline UB & 0.841 & 0.84 & 0.515 & 0.601 & 0.41 & Yes & No \\
\hline PS & 0.828 & 0.835 & 0.391 & 0.526 & 0.34 & No & Yes \\
\hline
\end{tabular}

Table 4. Reliability and construct validity 


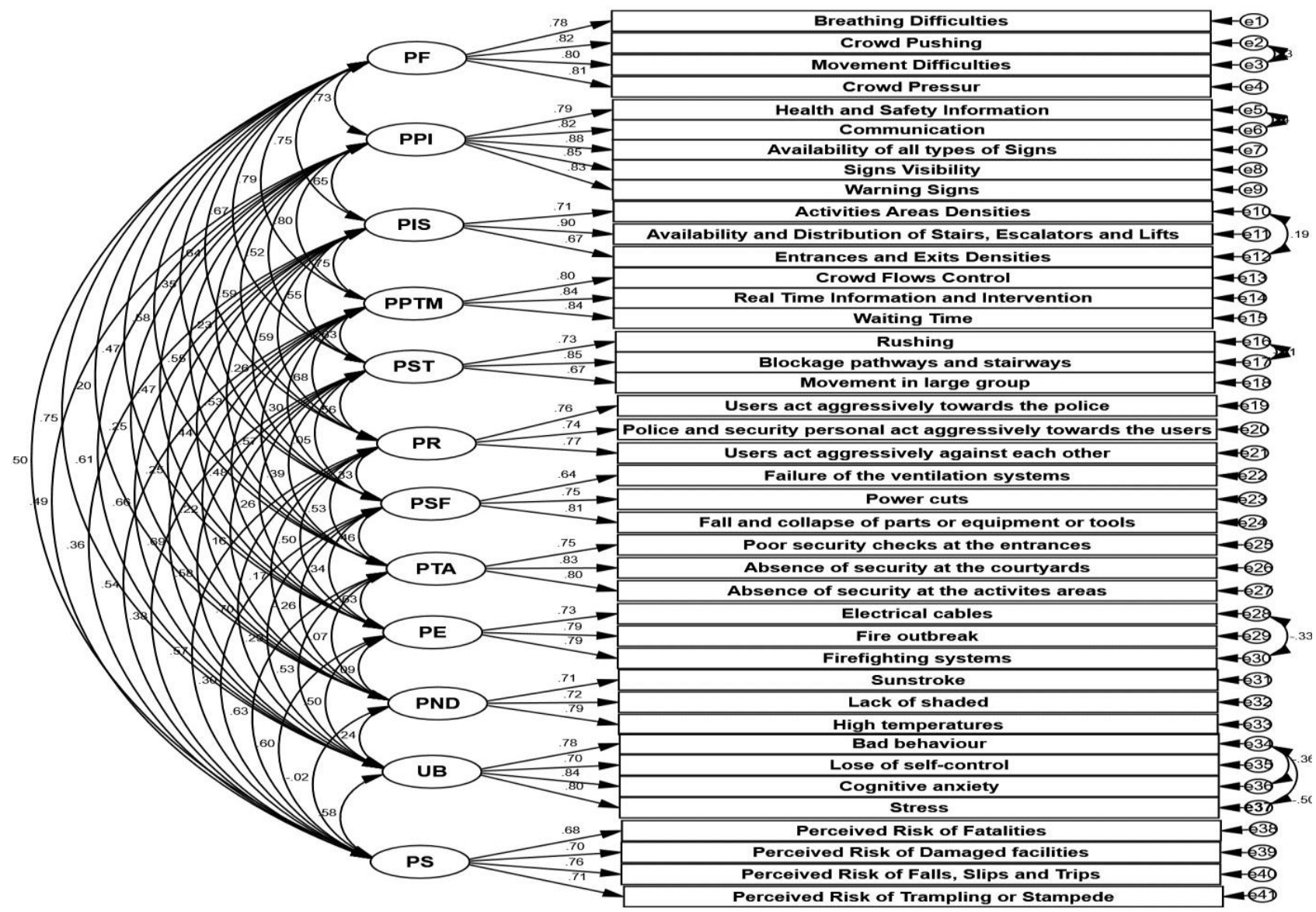

Fig. 3. Path diagram of the confirmatory factor analysis for all variables

Table 5. KMO and Bartlett's Test

\begin{tabular}{ccccc}
\hline \multirow{2}{*}{ Variables } & $\begin{array}{c}\text { Kaiser-Meyer-Olkin Measure of } \\
\text { Sampling Adequacy }\end{array}$ & \multicolumn{3}{c}{ Bartlett's Test of Sphericity } \\
\cline { 3 - 5 } & .897 & 7078.170 & 15 & P-value \\
\cline { 3 - 5 } PF & .887 & 7012.245 & 10 & .000 \\
PPI & .837 & 4611.010 & 10 & .000 \\
PIS & .844 & 4576.378 & 10 & .000 \\
PPRTM & .743 & 2673.446 & 15 & .000 \\
PRS & .713 & 1856.586 & 3 & .000 \\
PRR & .717 & 1854.211 & 6 & .000 \\
PRSF & .811 & 3207.841 & 6 & .000 \\
PRTA & .667 & 1736.834 & 3 & .000 \\
PRE & .748 & 2474.099 & 10 & .000 \\
PRND & .806 & 3989.596 & 10 & .000 \\
UB & .861 & 4748.904 & 28 & .000 \\
PS & & & .000 \\
\hline
\end{tabular}

\subsection{Confirmatory Factor Analysis (CFA) after Constraints}

Having ensured that the collected data was clean and normally distributed, the Kaiser-Meyer-Olkin (KMO) and Bartlett's Test was used to check whether the data was appropriate to continue with a CFA procedure (Raston et al., 2010). KMO and Bartlett's Test of Sphericity, as shown in Table 5, indicates that all values of independent and dependent variables have achieved the minimum level of 0.60 with a significant $p$-value $p<0.05$. The CFA results as presented in Fig. 3 presents the structural model, some modifications have been made based on Modification Indices (MI). Several items have been deleted one at a 
time and others have been covarying the error terms with the purpose of achieving the minimum fitness index.

\section{Convergent Validity}

To establish convergent validity, the model fit must be adequate, and the average variance extracted (AVE) must exceed 0.50 (Hair et al., 2010).

Table 6 provides the result of the model fit measures. $\mathrm{Hu}$ and Bentler, (1999) and Awang (2015) recommend a comparative fit index $(\mathrm{CFI}) \geq 0.90$, standardized root mean square residual $(\mathrm{SRMR}) \leq 0.08$, and root mean square error of approximation(RMSEA) $\leq 0.06$ for acceptable model fit. The values included in Table 6 indicate that the model is fit and all measures of CFI = 0.940, SRMR $=0.046$, and RMSEA $=0.045$ have achieved the required level. Also, the results of AVE for all constructs as illustrated in Table 8 have achieved the standard minimum required level of 0.50 .

\section{Discriminant Validity}

To establish discriminant validity three criteria must be met (Gaskin, 2016a; Hair et al., 2010). The FornellLarcker test needs the square root AVE for each construct to be greater than any inter-construct correlations (Fornell and Larcker, 1981). All constructs of this study have met this criterion. The square root of the AVE of the construct is greater than its estimates of correlation as presented in Table 7
The other two criteria for discriminant validity that must also be met are the Maximum Shared Squared Variance (MSV) and Average Shared Squared Variance (ASV). Hair et al., (2010) recommend that MSV and ASV must be less than the results of AVE (MSV<AVE, ASV $<$ AVE). The results of ASV and MSV as detailed in Table 8 indicate that our measurement model is valid.

\section{Reliability and Construct Validity}

Table 8presents the results of the reliability and construct validity test. Two reliability tests have been undertaken for this study: composite reliability (CR) and Cronbach's alpha. Both tests were used to guarantee the reliability of the data before conducting further analysis. CR is more accurate than Cronbach's alpha because it does not assume that the loadings or error terms of the items are equal (Chin et al., 2003). The CR test has met the standard minimum threshold of 0.60 .

The model also confirms that all Cronbach's Alpha values for the construct as given in Table 4 are above the recommended value of 0.70 (Gaskin, 2016b; Peterson and Peterson, 1994). This indicates the acceptability of internal consistency and confirms that all the items used in the model are technically free from the errors (Hair et al., 2010).

Overall, the result of the assessment of the measurement model shows solid evidence of unidimensionality, convergent validity, discriminant validity, and reliability.

Table 6. Fit indices

\begin{tabular}{cccc}
\hline Measure & Estimate & Threshold & Interpretation \\
\hline CFI & 0.940 & $>0.95$ & Good fit \\
SRMR & 0.046 & $<0.08$ & Good fit \\
RMSEA & 0.045 & $<0.06$ & Good fit \\
\hline
\end{tabular}

Table 7. Discriminant validity Fornell-Larcker test

\begin{tabular}{|c|c|c|c|c|c|c|c|c|c|c|c|c|}
\hline Construct & 1 & 2 & 3 & 4 & 5 & 6 & 7 & 8 & 9 & 10 & 11 & 12 \\
\hline PF & 0.802 & & & & & & & & & & & \\
\hline PPI & 0.735 & 0.835 & & & & & & & & & & \\
\hline PIS & 0.746 & 0.655 & 0.770 & & & & & & & & & \\
\hline PPRTM & 0.789 & 0.802 & 0.746 & 0.828 & & & & & & & & \\
\hline PRS & 0.669 & 0.523 & 0.547 & 0.627 & 0.753 & & & & & & & \\
\hline PRR & 0.637 & 0.591 & 0.587 & 0.684 & 0.557 & 0.760 & & & & & & \\
\hline PRSF & 0.354 & 0.234 & 0.260 & 0.301 & 0.045 & 0.331 & 0.737 & & & & & \\
\hline PRTA & 0.578 & 0.551 & 0.528 & 0.573 & 0.388 & 0.532 & 0.458 & 0.794 & & & & \\
\hline PRE & 0.468 & 0.468 & 0.438 & 0.480 & 0.257 & 0.504 & 0.339 & 0.634 & 0.768 & & & \\
\hline PRND & 0.196 & 0.253 & 0.253 & 0.218 & 0.164 & 0.175 & -0.260 & -0.068 & -0.091 & 0.741 & & \\
\hline UB & 0.749 & 0.608 & 0.662 & 0.692 & 0.584 & 0.696 & 0.292 & 0.532 & 0.496 & 0.236 & 0.785 & \\
\hline PS & 0.502 & 0.492 & 0.360 & 0.542 & 0.381 & 0.569 & 0.302 & 0.633 & 0.599 & -0.019 & 0.581 & 0.713 \\
\hline
\end{tabular}


Table 8. Reliability and construct validity

\begin{tabular}{lccccccc}
\hline Constructs & $\begin{array}{c}\text { CR } \\
\text { (above 0.60) }\end{array}$ & $\begin{array}{c}\text { AVE } \\
\text { (above 0.50) }\end{array}$ & $\begin{array}{c}\text { Cronbach } \\
\text { (above 0.7) }\end{array}$ & MSV & ASV & $\begin{array}{c}\text { Convergent } \\
\text { validity } \\
\text { CR }>\text { AVE } \\
\text { AVE }>0.50\end{array}$ & $\begin{array}{c}\text { Discriminant } \\
\text { validity } \\
\text { MSV }<\text { AVE } \\
\text { AVV }\end{array}$ \\
\hline PF & 0.878 & 0.644 & 0.886 & 0.622 & 0.37 & Yes & Yes \\
\hline PPI & 0.920 & 0.697 & 0.922 & 0.643 & 0.32 & Yes & Yes \\
\hline PIS & 0.811 & 0.593 & 0.824 & 0.556 & 0.31 & Yes & Yes \\
\hline PPRTM & 0.867 & 0.685 & 0.866 & 0.643 & 0.38 & Yes & Yes \\
\hline PRS & 0.796 & 0.568 & 0.748 & 0.448 & 0.22 & Yes & Yes \\
\hline PRR & 0.803 & 0.577 & 0.804 & 0.484 & 0.31 & Yes & Yes \\
\hline PRSF & 0.779 & 0.543 & 0.774 & 0.210 & 0.09 & Yes & Yes \\
\hline PRTA & 0.836 & 0.630 & 0.833 & 0.403 & 0.27 & Yes & Yes \\
\hline PRE & 0.811 & 0.590 & 0.780 & 0.403 & 0.21 & Yes & Yes \\
\hline PRND & 0.785 & 0.549 & 0.784 & 0.068 & 0.04 & Yes & Yes \\
\hline UB & 0.864 & 0.616 & 0.834 & 0.561 & 0.33 & Yes & Yes \\
\hline PS & 0.805 & 0.508 & 0.804 & 0.401 & 0.23 & Yes & Yes \\
\hline & & & & & &
\end{tabular}


34 Alkhadim, M., Gidado, K., and Painting, N.

Table 9. Factor loading for items

\begin{tabular}{|c|c|c|}
\hline Constructs & Items & Factor Loading \\
\hline \multicolumn{3}{|l|}{$\mathrm{PF}$} \\
\hline & Breathing Difficulties & 0.78 \\
\hline & Crowd Pushing & 0.82 \\
\hline & Movement Difficulties & 0.80 \\
\hline & Crowd Pressure & 0.81 \\
\hline \multicolumn{3}{|l|}{ PPI } \\
\hline & Health and Safety Information & 0.80 \\
\hline & Communication & 0.82 \\
\hline & Availability of all types of Signs & 0.88 \\
\hline & Signs Visibility & 0.85 \\
\hline & Warning Signs & 0.83 \\
\hline \multicolumn{3}{|l|}{ PIS } \\
\hline & Activities Areas Densities & 0.71 \\
\hline & $\begin{array}{l}\text { Availability and Distribution } \\
\text { of Stairs, Escalators, and Lifts }\end{array}$ & 0.91 \\
\hline & Entrances and Exits Densities & 0.67 \\
\hline \multicolumn{3}{|l|}{ PPRTM } \\
\hline & Crowd Flows Control & 0.80 \\
\hline & Real Time Information and Intervention & 0.84 \\
\hline & Waiting Time & 0.84 \\
\hline \multicolumn{3}{|l|}{ PRS } \\
\hline & Rushing & 0.73 \\
\hline & Blockage pathways and stairways & 0.85 \\
\hline & Movement in large group & 0.67 \\
\hline \multicolumn{3}{|l|}{ PRR } \\
\hline & Users act aggressively to the police & 0.76 \\
\hline & Police and security personal act aggressively towards the users & 0.74 \\
\hline & Users act aggressively against other & 0.78 \\
\hline \multicolumn{3}{|l|}{ PRSF } \\
\hline & Failure of the ventilation systems & 0.65 \\
\hline & Power cuts & 0.75 \\
\hline & Fall and collapse of parts or equipment & 0.81 \\
\hline \multicolumn{3}{|l|}{ PRTA } \\
\hline & Poor security checks at the entrances & 0.75 \\
\hline & Absence of security at the courtyards & 0.83 \\
\hline & Absence of security at the activities areas & 0.80 \\
\hline \multicolumn{3}{|l|}{ PRE } \\
\hline & Electrical cables & 0.73 \\
\hline & Fire outbreak & 0.79 \\
\hline & Firefighting systems & 0.79 \\
\hline
\end{tabular}


Table 9. Factor loading for items (continued)

\begin{tabular}{|c|c|c|}
\hline Constructs & Items & Factor Loading \\
\hline \multicolumn{3}{|l|}{ PRND } \\
\hline & Sunstroke & 0.71 \\
\hline & Lack of shaded & 0.72 \\
\hline & High temperatures & 0.79 \\
\hline \multicolumn{3}{|l|}{ UB } \\
\hline & Bad behavior & 0.78 \\
\hline & Loss of self-control & 0.70 \\
\hline & Cognitive anxiety & 0.85 \\
\hline & Stress & 0.80 \\
\hline \multicolumn{3}{|l|}{ PS } \\
\hline & Perceived Risk of Fatalities & 0.68 \\
\hline & Perceived Risk of Damaged facilities & 0.71 \\
\hline & Perceived Risk of Falls, Slips\& Trips & 0.76 \\
\hline & Perceived Risk of Trampling or Stampede & 0.71 \\
\hline
\end{tabular}

\section{Conclusion}

This research has identified 12 critical risk constructs in crowded large space buildings and undertook a confirmatory factor analysis to verify and validate these constructs. This analysis undertaken by using the data collected from one of the largest events in the world held in the largest Mosque that can accommodate up to 1.2 million people. The paper presented the results of confirmatory factor analysis examining twelve important variables in perceived crowd safety. The theoretical pattern of the variables loading on a developed construct was tested confirming the validity and reliability of the model. It clearly shows that the items on each construct of the study are reliable and the model has got enough measurement properties. Forty-one items were identified with an acceptable factor loading of at least 0.60 . The results have shown good internal consistency and validity of the constructs thus supporting the potential use of these 12 critical risk constructs in crowded large space buildings for further studies. For instance, the model can be used as indicators to evaluate large buildings used for large numbers of people whether or not it involved any of these risk items.

In crowded large space buildings, the 12 critical risk constructs and 41 indicators must be included in the risk assessment sheet by the facilities managers and those who are concern about the safety during an event. These indicators can be used as a safety measure to reduce the risks and to ensure the venue is under control from serious dangers. Most of the risks identified were the causes of many crowd disasters over the world were either not recognized or completely ignored. Therefore, identifying the comprehensive risk factors is necessary which will assist the facilities managers and others to recognize them as they manage the facility and the event. The five steps of risk assessment are recommended to be used including look for the hazards, decide who might be harmed and how, evaluate the risks and decide whether the existing precautions are adequate or whether more should be done, record the findings, and review the assessment and revise it if necessary. Focusing on the objective safety alone ensuring the design, spaces, and necessary tools etc. are in place is insufficient. Addressing this does not mean that the venue is fully safe. The safety in crowded large space buildings must rely on both the objective safety and subjective safety and both need to be measured. Having all the necessary planning and precautions without measuring the subjective safety, the possibility of major crowd disasters is still high. For instance, in the event of an emergency, when people feel unsafe, serious crowd disasters may occur.

This paper has covered most of the risk factors that may lead to crowd disasters. It also confirmed that it is not only the physical items that facilities managers places in crowded large space buildings but also the behaviour of the users as they occupy the space which may also be triggered by some other external factors. It is now established that the subjective safety of user has to be included in the future risk assessment of crowded large space buildings and subsequent safety management strategy in such facility. We concluded therefore that these 12 constructs and items listed in Table 9 must be taken into account for managing large space buildings to enhance crowd safety and reduce risk.

Several limitations were identified in the early stage of the study and resolved, however, not all limitations were addressed and dealt with. One of the limitations is that the study could not cover all the characteristic of the population. Because the sample population is large (nearly two million pilgrims) with several heterogeneous strata (groups), the population elements were divided into homogenous segments according to the culture and nationalities. There was some difficulty of access to the women sections due to religious and cultural reasons, the study lacked from female participants. Another limitation is that the study has not examined the direct and indirect effect among the variables. Lastly, it was only tested in the religious crowded building which can be tested in the future in different other crowded large space buildings such as sports stadiums, concert halls, night clubs etc. 


\section{Acknowledgements}

The authors gratefully acknowledge the support of the "The Custodian of The Two Holy Mosques Institute for Hajj and Umrah Research, Makkah".

\section{References}

Ali, I. M., Hashim, A. E., and Isnin, Z. (2011). Spectators Safety Awareness in Outdoor Stadium Facilities. Procedia Engineering (on-line), 20: 98-104. http://dx.doi.org/10.1016/j.proeng.2011.11.143.

Allport, F. H. (1924). Social Psychology. Routledge/Thoemmes Press.

Alnabulsi, H. and Drury, J. (2014). Social identification moderates the effect of crowd density on safety at the Hajj. Proceedings of the National Academy of Sciences of the United States of America (on-line), 111: 9091-9096. http://www.ncbi.nlm.nih.gov/pubmed/24927593.

Alsolami, B., Embi, M. R., and Enegbuma, W. I. (2016). The Influence of Personal Factors on Hajj Crowd Perception among African Pilgrim Group in Mina. Indian Journal of Science and Technology, 9: 9.

Anderson, C. A. (2001). Heat and Violence. Current Directions in Psychological Science (on-line), 10: 3338. http://cdp.sagepub.com/lookup/doi/10.1111/14678721.00109.

Ascoura, I. E. (2013). Impact of Pilgrimage (Hajj) on the Urban Growth of the Mecca. Journal of Educational and Social Research, 3: 255-264. http://www.mcser.org/journal/index.php/jesr/article/vi ew/163.

Awang, Z. (2015). SEM Made Simple: A Gentle Approach to Learning Structural Equation Modeling. MPWS Rich Publication 2015.

Awang, Z., Afthanorhan, A., and Mohamad, M. (2015). An evaluation of measurement model for medical tourism research: The confirmatory factor analysis approach. International Journal of Tourism Policy.

Berlonghi, A. E. (1995). Understanding and planning for different spectator crowds. Safety Science, 18: 239247.

BIFM (2014). The Facilities Management Professional Standards.

Le Bon, G. (1896). The Crowd: A Study of the Popular Mind.

Booty, F. (2009). Facilities Management Handbook (FOURTH EDI). Library of Congress.

Burkle, F. M. and Hsu, E. B. (2011). Ram Janki temple: Understanding human stampedes. The Lancet (online), 377: 106-107. http://dx.doi.org/10.1016/S01406736(10)60442-4.

Center for Research on the Epidemiology of Disasters (CRED) (2003). Disaster Criteria (on-line). http://www.emdat.be/explanatory-notes.

Challenger, R., Clegg, C. W. and Robinson, M. A. (2009a). Understanding Crowd Behaviours: Supporting Documentation. Cabinet Office.

Challenger, R., Clegg, C. W. and Robinson, M. A. (2009b). Understanding Crowd Behaviours: Supporting evidence. Cabinet Office.

Chin, W. W., Marcoling, B. L., and Newsted, P. R. (2003). A partial least squares latent variable modeling approach for Measuring Interaction Effects:
Results from a Monte Carlo Simulation Study and an Elctronic-Mail Emotion/Adoption Study. Information System Research, 14: 189-217.

Chinda, T. (2011). The Use of Safety Assessment Approach in Improving Safety: Case Studies. Journal of Engineering, Project, and Production Management, 20-21.

Choi, Y. (2013). A structural equation model of the determinants of repeat purchase behaviour of online grocery shoppers in the UK.

Chukwuma, A. and Kingsley, C. (2014). Disaster Risks in Crowded Situations: Contemporary Manifestations and Implications of Human Stampede in Nigeria. International Journal of Liberal Arts and Social Science, 2: 87-98.

Creswell, J. W. (2014). Research Design (International Student Edition): Qualitative, Quantitative, and Mixed Methods Approaches (4th ed). SAGE Publications, 2013.

Daniel, J. (2011). Sampling Essentials: Practical Guidelines for Making Sampling Choices. SAGE, 2011.

David V. Canter, Miriam Comber, D. L. U. (1989). Football in Its Place: An Environmental Psychology of Football Grounds. Routledge, 1989.

Dawson, C. P. and Watson, A. E. (2000). Measures of Wilderness Trip Satisfaction and User Perceptions of Crowding. USDA Forest Service Proceedings RMRS, 4: 93-98.

Dear, K. and Wang, Z. (2015). Climate and health: Mortality attributable to heat and cold. The Lancet, 386: 320-322.

Diaz, J., Linares, C., and Tobias, A. (2006). A critical comment on heat wave response plans. European Journal of Public Health, 16: 600.

Dickie, J. F. (1995). Major crowd catastrophes. Safety Science, 18: 309-320.

DiPasquale, D. and Glaeser, E. L. (1996). The Los Angeles Riot and the Economics of Urban Unrest Denise. NBER Working Paper Series (on-line), 43: 52-78. http://papers.nber.org/papers/w5456.pdf.

Fornell, C. and Larcker, D. F. (1981). Structural Equation Models With Unobservable Variables and Measurement Error: Algebra and Statistics. Journal of Marketing Research, 382-388.

Fruin, J. J. (1993). The causes and prevention of crowd disasters. Engineering for crowd safety: 1-10.

Gaskin, J. (2016a). Confirmatory Factor Analysis. Gaskination's StatWiki (on-line). http://statwiki.kolobkreations.com/index.php?title=Co nfirmatory_Factor_Analysis.

Gaskin, J. (2016b). Exploratory Factor Analysis. Gaskination's StatWiki (on-line). http://statwiki.kolobkreations.com.

Gaskin, J. and Lim, J. (2016). Model Fit Measures. Gaskination's StatWiki, AMOS Plugi.

Goldblatt, J. (1996). Event Management . Festival Management and Event Tourism, 4: 157-158.

Graefe, A. R., Vaske, J. J., and Kuss, F. R. (1984). Social carrying capacity: An integration and synthesis of twenty years of research. Leisure Sciences, 6: 395431.

Hair, J. F., Black, W. C., Babin, J., and Anderson, R. E. 
(2010). Multivariate data analysis (7th ed). Pearson, 2009.

Helbing, D. and Mukerji, P. (2012). Crowd disasters as systemic failures: analysis of the Love Parade disaster. EPJ Data Science, 1: 1-40.

Hoseini, S. H., Aslankhani, M. A., Abdoli, B. and Mohammadi, F. (2011). The relationship between the number of crowds with anxiety and the function of the soccer premier league's referees. Procedia - Social and Behavioral Sciences (on-line), 30: 2374-2378. http://dx.doi.org/10.1016/j.sbspro.2011.10.463.

HSE, S. E. (2000). Managing crowds safely. Review Literature And Arts Of The Americas: 1-63.

Hu, L. and Bentler, P. M. (1999). Cutoff criteria for fit indexes in covariance structure analysis: Conventional criteria versus new alternatives. Structural Equation Modeling: A Multidisciplinary Journal, 6: 1-55.

Illiyas, F. T., Mani, S. K., Pradeepkumar, A. P., and Mohan, K. (2013). Human stampedes during religious festivals: A comparative review of mass gathering emergencies in India. International Journal of Disaster Risk Reduction (on-line), 5: 10-18. http://dx.doi.org/10.1016/j.ijdrr.2013.09.003.

International Labour Office (1988). Major Hazard Control: A Practical Manual : an ILO Contribution to the International Programme on Chemical Safety of UNEP, ILO, WHO (IPCS). Cambridge: International Labour Organization, 1988. https://books.google.co.uk/books?id=694e5QW8WR QC.

Kalkstein, L. S. and Greene, J. S. (1997). An evaluation of climate/mortality relationships in large U.S. cities and the possible impacts of a climate change. Environmental Health Perspectives, 105: 84-93.

Kemp, C. and Moore, T. (2010). A review of the management of crowd safety at outdoor street special events.

Kim, D., Lee, K., and Sirgy, J. (2016). Examining the differential impact of human crowding versus spatial crowding on visitor satisfaction at a festival. Journal of Travel \& Tourism Marketing (on-line), 33: 293312.

http://www.tandfonline.com/doi/full/10.1080/1054840 8.2015.1024914.

Leopkey, B. and Parent, M. M. (2009). Risk Management Issues in Large-scale Sporting Events: a Stakeholder Perspective Risk Management Issues in Large-scale Sporting Events: a Stakeholder Perspective. European Sport Management Quarterly, 9.

Lloyd, K., Rosin, P. L., Marshall, D., and Moore, S. C. (2017). Detecting violent and abnormal crowd activity using temporal analysis of grey level co-occurrence matrix ( GLCM ) -based texture measures. Machine Vision and Applications.

Lowe, D., Ebi, K. L., and Forsberg, B. (2011). Heatwave early warning systems and adaptation advice to reduce human health consequences of heatwaves. International Journal of Environmental Research and Public Health, 8: 4623-4648.

Lum, C., Kennedy, L. W., and Sherley, A. (2006). Are counter-terrorism strategies effective? the results of the Campbell systematic review on counter-terrorism evaluation research. Journal of Experimental
Criminology, 2: 489-516.

Mehta, V. (2013). The Street: A Quintessential Social Public Space. Routledge, 2013.

Miller, K. (2015). Behind the Mecca Stampede: When Crowd Mentality Meets Panic. Yahoo, 2015.

Moller, N., Hansson, S. O. V. E., and Peterson, M. (2006). Safety is more than the antonym of risk. Journal of Applied Philosophy, 23: 419-432.

Myers, D. G. (1990). Social Psychology (3rd Edition). McGraw-Hill, 1990.

National Disaster Management Authority (NDMA) (2014). Managing Crowd at Events and Venues of Mass Gathering.

Nicholson, C. E. and Roebuck, B. (1995). The investigation of the Hillsborough disaster by the Health and Safety Executive. , 18: 249-259.

O'Connell, T. S. B. C. (2009). Group Dynamics in Recreation and Leisure: Creating Conscious Groups Through an Experiential Approach (illustrate). Human Kinetics, 2009.

Oakes, S. and North, A. C. (2008). Using music to influence cognitive and affective responses in queues of low and high crowd density. Journal of Marketing Management (on-line), 24: 589-602. http://www.informaworld.com/openurl?genre=article \&doi $=10.1362 / 026725708 X 326002 \&$ magic $=$ crossref.

Patz, J. a, Engelberg, D., and Last, J. (2000). The effects of changing weather on public health. Annual review of public health, 21: 271-307.

Peterson, R. A. and Peterson, R. A. (1994). A Metaanalysis of Cronbach's Coefficient Alpha. Journal of Consumer Research, 21.

Petroski, H. (1992). To Engineer is Human: The Role of Failure in Successful Design.

Rahmat, N., Jusoff, K., Ngali, N., Ramli, N., Md Zaini, Z. M., Samsudin, A., Abd Ghani, F., and Hamid, M. (2011). Crowd Management Strategies and Safety Performance among Sports Tourism Event Venue Organizers in Kuala Lumpur and Selangor. World Applied Sciences Journal, 12: 47-52.

Raineri, A. S. (2015). Behavioural risk at outdoor music festivals University of Southern Queensland Behavioural risk at outdoor music festivals.

Richard L. Best, N. F. P. A. (1978). Reconstruction of a tragedy: the Beverly Hills Supper Club fire, Southgate, Kentucky, May 28, 1977. National Fire Protection Association, 1978.

Riebau, A. R. and Qu, J. J. H. (2005). Natural Disasters and Extreme Events in Agriculture. M.V.K. Sivakumar, R.P. Motha \& H.P. Das (eds). Berlin/Heidelberg: $\quad$ Springer-Verlag. http://www.springerlink.com/index/10.1007/3-54028307-2\%5Cnhttp://link.springer.com/10.1007/3-54028307-2.

Robine, J. M., Cheung, S. L. K., Le Roy, S., Van Oyen, H., Griffiths, C., Michel, J. P., and Herrmann, F. R. (2008). Death toll exceeded 70,000 in Europe during the summer of 2003. Comptes Rendus - Biologies, 331: 171-178.

Sagun, A., Anumba, C. J., and Bouchlaghem, D. (2013). Designing Buildings to Cope with Emergencies: Findings from Case Studies on Exit Preferences. Buildings, 3: 442-461. 
Sagun, A., Bouchlaghem, D., and Anumba, C. J. (2008). Building Design Information and Requirements for Crowd Safety During Disasters. Resilient Organisations.

Schutt, R. (2006). Investigating the Social World with SPSS Student Version 14.0: The Process and Practice of Research (5th editio). Pine Forge Press, 2006.

Shaluf, I. M. (2007). Disaster types. Disaster Prevention and Management: An International, 16: 704-717.

Shaluf, I. M. (2008). Technological disaster stages and management. Disaster Prevention and Management, 17: $114-126$

Shaluf, I. M. and Ahmadun, F.-R. (2006). Disaster types in Malaysia: an overview. Disaster Prevention and Management (on-line), 15: 286-298. http://www.emeraldinsight.com/10.1108/0965356061 0659838.

Shiwakoti, N. and Sarvi, M. (2013). Understanding pedestrian crowd panic: A review on model organisms approach. Journal of Transport Geography (on-line), 26:

$12-17$. http://dx.doi.org/10.1016/j.jtrangeo.2012.08.002.

Silke, a. (2001). The Devil You Know: Continuing Problems with Research on Terrorism. Terrorism and Political Violence, 13: 1-14.

Silvers, J. R. (2008). Risk Management for Meetings and Events (illustrate). Butterworth-Heinemann, 2008.

Sime, J. D. (1999). Crowd facilities, management and communications in disasters. Facilities, 17: 313-324.

Sime, J. D. (1995). Crowd psychology and engineering. Safety science (on-line), 21: 1-14. http://www.sciencedirect.com/science/article/pii/0925 753596810113.

Sime, J. D. (1995). Crowd psychology and engineering. Safety Science, 21: 1-14.

Sorensen, M. and Mosslemi, M. (2009). The Effect of Road Safety Measures on Subjective Safety among Vulnerable Road Users.

Still, G. K. (2000). Crowd dynamics. University of Warwick.

http://webcat.warwick.ac.uk/record=b1371042 S1.

Still, G. K. (2016). Crowd safety and Risk analysis (online).

http://www.gkstill.com/ExpertWitness/CrowdDisaster s.html.

Taylor, A. H., Daniel, J. V., Leith, L., and Burke, R. J. (1990). Perceived stress, psychological burnout and paths to turnover intentions among sport officials. Journal of Applied Sport Psychology, 2: 84-97.

The Regional Office for Europe of the World Health Organization (2011). Heat-Health Action Plan. World Health Organization: 60.

Tilly, C. (2004). Terror, Terrorism, Terrorists. In: Sociological Theory. pp.5-13. http://stx.sagepub.com/lookup/doi/10.1111/j.14679558.2004.00200.x.

Torrens, P. M. and McDaniel, A. W. (2012). Modeling Geographic Behavior in Riotous Crowds. Annals of the Association of American Geographers, 103: 120619095844009.

Tseng, Y. P., Kyle, G. T., Shafer, C. S., Graefe, A. R., Bradle, T. a., and Schuett, M. a. (2009). Exploring the crowding-satisfaction relationship in recreational boating. Environmental Management, 43: 496-507.

US DoD (2015). Department of Defense Dictionary of Military and Associated Terms. US Department of Defense Joint Publication, 2001: 1-513.

Westover, T. N. (1981). Perceived Crowding in Recreational Settings: An Environment-Behavior Model. Environment and Behavior, 21: 258-276.

Wieringa, S., Daamen, W., Hoogendoorn, S., and Gelder, V. (2016). Framework to mitigate risks of crowd disasters at mass events in public urban space. Transportation Research Board (TRB).

Yang, S. and Wyckoff, L. A. (2010). Perceptions of safety and victimization: does survey construction affect perceptions? Journal of Experimental Criminology: 293-323.

Yokota, J. (2005). Crush Syndrome in Disaster. Japan Medical Association Journal (JMAJ), 48: 341-352.

Zhuang, X. and Wu, C. (2012). The safety margin and perceived safety of pedestrians at unmarked roadway. Transportation Research Part F: Traffic Psychology and Behaviour (on-line), 15: 119-131. http://dx.doi.org/10.1016/j.trf.2011.11.005.

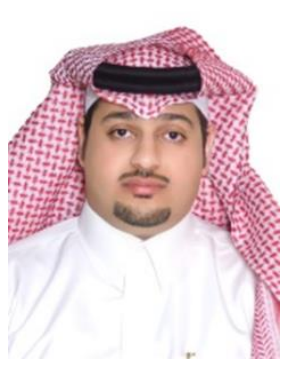

Mohammed Alkhadim is a $\mathrm{PhD}$ student in the School of Environment and Technology at the University of Brighton. Currently, he is working on a project examining the interrelationship between the user behaviour and perceived safety in the Holy Mosque to enhance the management of crowd safety in order to minimize the likelihood of crowd disaster during Hajj.

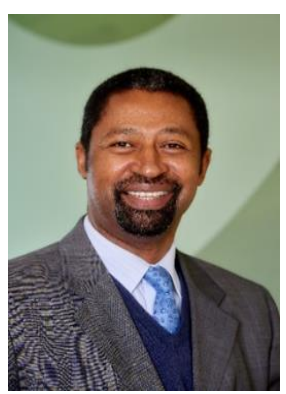

Kassim is a Chartered Construction Manager, Chartered Building Engineer and a Fellow of the chartered association of building engineers with over 35 years of experience as a practitioner in the construction industry and academia. $\mathrm{He}$ practiced as an engineer and project manager in both the private and public sectors in a number of countries. He advised governments and captains of industry on strategic and policy issues especially regarding private sector participation in the provision of infrastructure. Kassim is the immediate past President of the International Association of Engineering, Project and Production Management (EPPM).

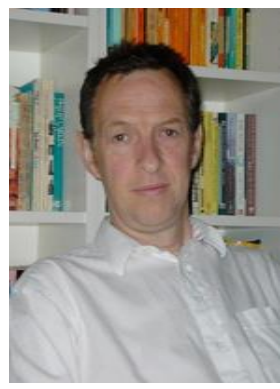

Noel has been at the University of Brighton since 1992. His research is in design, procurement and cost management on which he lectures at undergraduate and post graduate levels and is currently supervising $3 \mathrm{PhD}$ students. Noel was a member of the ARCOM scientific committee member from 20062012 and is currently an external 
examiner at Sheffield Hallam University. He has validated courses internationally and has been part of six CIAT accreditation panels for BSc Architectural Technology courses. Prior to (and on sabbatical from) the University of Brighton Noel has worked for a French Shipyard on an oil rig project, for a project management firm based in Brussels (which included working on projects in Cote d'Ivoire and the Democratic Republic of Congo) and well as commercial projects in Belgium. Before that Noel worked for commercial and social housing organisations and on site for consulting engineers on major motorway projects. He carries out work as a consultant to a major outdoor music promotor (and is fairly fluent in French). 